\title{
Effect of high pH on growth of Synechocystis sp. PCC 6803 cultures and their contamination by golden algae (Poterioochromonas sp.)
}

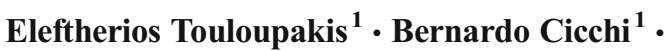 \\ Ana Margarita Silva Benavides ${ }^{2,3}$ • Giuseppe Torzillo ${ }^{1}$
}

Received: 8 July 2015 /Revised: 31 August 2015 / Accepted: 8 September 2015 /Published online: 6 November 2015

(C) The Author(s) 2015. This article is published with open access at Springerlink.com

\begin{abstract}
Culturing cyanobacteria in a highly alkaline environment is a possible strategy for controlling contamination by other organisms. Synechocystis PCC 6803 cells were grown in continuous cultures to assess their growth performance at different $\mathrm{pH}$ values. Light conversion efficiency linearly decreased with the increase in $\mathrm{pH}$ and ranged between $12.5 \%$ (PAR) at $\mathrm{pH} 7.5$ (optimal) and decreased to $8.9 \%$ at $\mathrm{pH} 11.0$. Photosynthetic activity, assessed by measuring both chlorophyll fluorescence and photosynthesis rate, was not much affected going from $\mathrm{pH} 7.5$ to 11.0 , while productivity, growth yield, and biomass yield on light energy declined by 32,28 , and $26 \%$ respectively at $\mathrm{pH} 11.0$. Biochemical composition of the biomass did not change much within $\mathrm{pH} 7$ and 10, while when grown at $\mathrm{pH} 11.0$, carbohydrate content increased by $33 \%$ while lipid content decreased by about the same amount. Protein content remained almost constant (average $65.8 \%$ of dry weight). Cultures maintained at $\mathrm{pH}$ above 11.0 could grow free of contaminants (protozoa and other competing microalgae belonging to the species of Poterioochromonas).
\end{abstract}

Electronic supplementary material The online version of this article (doi:10.1007/s00253-015-7024-0) contains supplementary material, which is available to authorized users.

Giuseppe Torzillo

torzillo@ise.cnr.it

1 Istituto per lo Studio degli Ecosistemi, CNR, Via Madonna del Piano 10, I-50019 Sesto Fiorentino, Italy

2 Escuela de Biología, Universidad de Costa Rica, San Pedro, San José 2060, Costa Rica

3 Centro de Investigación en Ciencias del Mar y Limnología (CIMAR), Universidad de Costa Rica, San Pedro, San José 2060, Costa Rica
Keywords Synechocystis PCC $6803 \cdot$ Poterioochromonas sp. Contamination $\cdot$ Fluorescence

\section{Introduction}

The cyanobacterium Synechocystis PCC 6803 is being widely used as a model organism for the study of photosynthetic processes, since it is well characterized and can easily be transformed. Moreover, its genome has already been completely sequenced, and a variety of mutants has become available. The use of Synechocystis PCC 6803 (hereafter Synechocystis) has been proposed for the production of biohydrogen as well as chemicals and biomaterials (Gao et al. 2012; Sharma et al. 2011; Yu et al. 2013; Englund et al. 2014). It has also been genetically engineered for the photosynthetic production of isoprene, a hydrocarbon currently used as feedstock in the synthetic chemistry industry for the production of commercial commodities (Chaves et al. 2015).

One of the major problems emerging in mass cultures is the lack of a reliable control of contamination by other microorganisms. Large-scale microalgae cultures like terrestrial crops can be attacked by pests and weeds causing devastating effects. Closed systems are usually recommended for strains growing in non-selective media. However, a number of recent reports have indicated that cultures in closed systems are often affected by contaminants in spite of their protection from the outside atmosphere (Rego et al. 2015; Hoffman et al. 2008; Forehead and O'Kelly 2013; Carney and Lane 2014; Zemke et al. 2013). Indeed, it has been found that in many cases, the main vehicle of the contamination is represented by the water used for preparing the medium.

One of the greatest dangers experienced by us in the mass cultivation of Synechocystis was represented by flagellates belonging to the species of Poterioochromonas 
(Synurophyceae). These are common members of the freshwater planktonic communities and possess digestive vacuoles in order to use phagotrophy to supplement phototrophic growth. They are very efficient phagotrophs, showing high growth rates, and have been identified as potential contaminants in Synechocystis mass cultures (Holen and Boraas 1995). Their growth is supported by a heterotrophic metabolism with cyanobacterial cells representing the feeding prey. In addition to the feeding mechanism, this kind of contamination has what can be defined a "killing effect" on the culture, as when these flagellates are phagotrophically active, they produce toxins with strong antibiotic effect (Leeper and Porter 1995; Blom and Pernthaler 2010).

It has been reported that, in order to prevent the growth of invading microorganisms in cyanobacteria cultures, the $\mathrm{pH}$ can be increased towards alkalinity since many cyanobacteria can still grow despite such harsh environmental conditions (Pikuta and Hoover 2007; McGinn et al. 2011). Synechocystis possesses a $\mathrm{CO}_{2}$-concentrating mechanism enabling them to acquire and concentrate inorganic carbon from the extracellular environment (Badger and Price 2003). Moreover, they can also utilize $\mathrm{HCO}_{3}{ }^{-}$as carbon source, by converting it to $\mathrm{CO}_{2}$ with the enzyme carbonic anhydrase. Many mechanisms have been suggested for $\mathrm{pH}$ homeostasis and the regulation of $\mathrm{CO}_{2} /$ $\mathrm{HCO}_{3}$ concentration, such as expression of proteins responsible for carbon assimilation and $\mathrm{pH}$ homeostasis, regulation of periplasmic carbonic anhydrase activity, or accumulation of acetolactate ions (Maestri and Joset 2000; Summerfield and Sherman 2008; Battchikova et al. 2010). Inorganic carbon availability is a key factor to consider when setting up a cyanobacterial cultivation at very alkaline $\mathrm{pH}$ since, at these $\mathrm{pH}$ values, inorganic carbon is mainly present as carbonate. Several experimental and modeling attempts have been made in order to elucidate how $\mathrm{pH}$ can affect cyanobacterial metabolism (Summerfield and Sherman 2008; Lopo et al. 2012).

In view of a potential utilization of Synechocystis in mass cultivation, and the necessity to prevent pollution of the culture by growing them at $\mathrm{pH}$ above the optimum, we wished to assess the effect of alkaline $\mathrm{pH}$ on productivity and on the level of contamination of the culture.

\section{Methods}

\section{Preparation of inoculum}

Synechocystis strain PCC 6803 cells (kindly provided by Prof. Tamagnini, IMI, Portugal) were pre-cultured in a BG11 medium under artificial irradiance of $50 \mu \mathrm{mol}$ photons $\mathrm{m}^{-2} \mathrm{~s}^{-1}$, supplied from one side of the cultivation columns (i.d. $=50 \mathrm{~mm}$; $400 \mathrm{~mL}$ working volume). The columns were placed in thermostatic bath at $28{ }^{\circ} \mathrm{C}$ and bubbled with a mixture of air- $\mathrm{CO}_{2}$ $(97 / 3 \mathrm{v} / \mathrm{v})$ at a continuous flow rate of $5 \mathrm{dm}^{3} \mathrm{~min}^{-1}$.

\section{Continuous culture}

A 1-L Pyrex Roux-type photobioreactor (PBR) with a flat cross section $(12 \times 5 \mathrm{~cm}$ width $)$ and a flat bottom was used. The culture was illuminated using cool white lamps (Dulux L, $55 \mathrm{~W} / 840$, Osram, Italy) with a fixed photon flux density (PFD) of $150 \mu \mathrm{mol}$ photons $\mathrm{m}^{-2} \mathrm{~s}^{-1}$. Mixing of the culture was achieved by means of a specially designed rotating impeller driven magnetically by a stirrer at the bottom (Giannelli et al. 2009). The $\mathrm{pH}$ of the culture was maintained at the preset value by automatic addition of $\mathrm{CO}_{2}$, while the temperature was maintained at a constant value of $28.0 \pm 0.2{ }^{\circ} \mathrm{C}$. The cultures were operated according to a continuous culture regime (chemostat) by imposing a fixed dilution rate $\left(D, \mathrm{~h}^{-1}\right)$ of $0.036 \mathrm{~h}^{-1}$. The culture was assumed to be at a steady state when the dry weight (DW) of the culture remained unchanged for at least $36 \mathrm{~h}$. The actual biomass yield on light energy was determined from the following equation: $Y_{\mathrm{kJ}}=(D \times V \times X) /$ $\left(A \times I_{\mathrm{a}}\right)$, where $D$ is the dilution rate $\left(0.036 \mathrm{~h}^{-1}\right), V$ is the working volume $(1 \mathrm{~L}), X$ is the cell concentration $\left(\mathrm{g} \mathrm{L}^{-1}\right), A$ is the area of the PBR exposed to light irradiation $\left(190 \mathrm{~cm}^{2}\right)$, and $I_{\mathrm{a}}$ is the intensity of light absorbed by the cells (in $\mu \mathrm{mol}$ photons $\mathrm{cm}^{-2} \mathrm{~h}^{-1}$ ).

\section{Analytical procedures}

DW was determined in duplicate by using $10-\mathrm{mL}$ samples taken from the culture daily. Samples were filtered through pre-weighted 47-mm-diameter glass microfiber membranes (Whatman GF/F filters, Maidstone, England). The cells were washed twice with deionized water and then oven-dried at $105^{\circ} \mathrm{C}$ until constant weight. Chlorophyll concentration was determined spectrophotometrically in triplicate $5-\mathrm{mL}$ samples which were centrifuged in glass tubes for $8 \mathrm{~min}$ at $2650 \mathrm{~g}$ in an ALC-PK110 centrifuge. The pellet was re-suspended in $5 \mathrm{~mL}$ of pure methanol, placed in a $70{ }^{\circ} \mathrm{C}$ water bath for $3 \mathrm{~min}$, and centrifuged again for $8 \mathrm{~min}$ at $2650 \mathrm{~g}$. The supernatant absorbance was measured at 665 and $750 \mathrm{~nm}$ against a pure methanol blind. The concentration of individual carotenoids was assessed using a reversed-phase Beckman System Gold HPLC (module 125 solvent) equipped with a diode array detector, model 168 Nouveau (Beckman Instruments, Inc., CA, USA), with a column Luna C8 (Phenomenex), in accordance with Van Heukelem and Thomas (2001). For phycobilisome measurements, culture samples $(5 \mathrm{~mL})$ were collected in tubes and centrifuged at $2650 \mathrm{~g}$ for $8 \mathrm{~min}$. The supernatant was discarded, and $0.5 \mathrm{~mL}$ of glass beads (diameter $0.17-0.18 \mathrm{~mm}$, B. Braun Biotech Int, Germany) was added to the sample, along with $200 \mu \mathrm{L}$ of $\mathrm{NaCl} 0.15 \mathrm{M}$ phosphate-buffered ( $\mathrm{pH}$ 7.4) solution. The mixture was vortexed for $10 \mathrm{~min}$ in order to break the cells; phosphate buffer was then added to reach a volume of $5 \mathrm{~mL}$. The tubes were centrifuged at $2650 \mathrm{~g}$ for $5 \mathrm{~min}$, and the supernatant was 
then transferred into $15-\mathrm{mL}$ Falcon tubes and centrifuged at $12,500 \mathrm{~g}$ for $10 \mathrm{~min}$.

The concentration of allophycocyanin (Apc) and phycocyanin $(\mathrm{Pc})$ was calculated according to Bennett and Bogorad (1973).

Protein determination was performed in triplicate according to Lowry et al. (1951). Total carbohydrate content was measured using the phenol-sulfuric acid method (Dubois et al. 1956). Lipids were extracted from $5 \mathrm{mg}$ of dry biomass using $1 \mathrm{~mL}$ of dichloromethane, $2 \mathrm{~mL}$ of methanol, and $0.8 \mathrm{~mL}$ of deionized water $(1: 2: 0.8, v / v / v)$. The mixture was vortexed and sonicated for $10 \mathrm{~min}$, after which an additional $1 \mathrm{~mL}$ of dichloromethane and $1 \mathrm{~mL}$ of deionized water were added. The mixture was then vortexed and centrifuged for $5 \mathrm{~min}$ at $1500 \mathrm{~g}$ (ALC-PK110). The bottom phase was recovered, placed in pre-weighted containers, and heated to complete evaporation. The extracted lipids were then weighed. Amino acid composition was determined according to Potenza et al. (2013). DNA was extracted by using the DNeasy Blood and Tissue Kit (Qiagen) using the manufacturer's protocol. DNA concentration was measured using the NanoDrop ND-1000 UV/Vis spectrophotometer according to the manufacturer's instructions (NanoDrop Technologies, USA).

Elemental composition analysis of the biomass was performed on lyophilized samples using a CHNOS analyzer (Flash EA, 1112 Series, Thermo Electron Corporation). Ash content was determined after heating the biomass at $450{ }^{\circ} \mathrm{C}$ for $24 \mathrm{~h}$. Lyophilized samples were analyzed for $\mathrm{Ca}, \mathrm{Mg}$, and $\mathrm{Na}$ concentrations by using an inductively coupled plasma emission spectrometer (PerkinElmer Optima 2000, Germany).

The heat of combustion $\left(\mathrm{kJ} \mathrm{g}^{-1}\right)$ of the biomass at the steady state was calculated by using the following formula: $([($ proteins $\times 5.7)+($ carbohydrates $\times 4.2)+($ lipids $\times 9.3)] /$ 100) $\times 4.184$.

\section{Fluorescence measurements}

Chlorophyll a fluorescence transients were recorded using a Handy PEA (Hansatech Instruments) in 2-mL dark-adapted samples illuminated with continuous light (650 nm peak wavelength, $3500 \mu \mathrm{mol}$ photons $\mathrm{m}^{-2} \mathrm{~s}^{-1}$ ) provided by lightemitting diodes. Each chlorophyll a fluorescence induction curve was analyzed using "Biolyzer HP3" software. Analysis of chlorophyll fluorescence quenching was carried out with a pulse-amplitude-modulation fluorometer (PAM2100, H. Walz, Effeltrich, Germany) operated by PC software PamWin (version 2.00f).

The ratio between variable and maximum fluorescence, $F_{\mathrm{v}} /$ $F_{\text {m }}$, was used to determine the maximum photochemical yield of photosystem II (PSII). For this purpose, samples were taken from the PBR and incubated in the dark for 15 min to remove any energy-dependent quenching. In addition, just before sending a flash for the $F_{\mathrm{m}}$ determination, a sample was illuminated with a 10-s-long far-red light pulse (above $700 \mathrm{~nm}$, $10 \mathrm{~W} \mathrm{~m}^{-2}$ ), supplied by the PAM-2100. The effective photochemical quantum yield of PSII $\Delta F / F_{\mathrm{m}}{ }^{\prime}=\left(F_{\mathrm{m}}{ }^{\prime}-F_{\mathrm{s}}\right) / F_{\mathrm{m}}{ }^{\prime}$, which is the number of electrons generated per photon absorbed, was measured using $F_{\mathrm{s}}$ and $F_{\mathrm{m}}{ }^{\prime}$, which represented the steady state and maximum fluorescence measured in the light. $F_{\mathrm{s}}$ and $F_{\mathrm{m}}{ }^{\prime}$ were measured in situ by pointing the fiber optic cable directly on the surface of the PBR and perpendicularly to the direction of the incident light.

Non-photochemical quenching (NPQ) was calculated by using the Stern-Volmer equation NPQ $=\left(F_{\mathrm{m}}-F_{\mathrm{m}}{ }^{\prime}\right) / F_{\mathrm{m}}{ }^{\prime}$ (Krause and Janhns 2004). $F_{0}{ }^{\prime}$ was estimated from the following relationship: $F_{0}{ }^{\prime}=F_{0} /\left(F_{\mathrm{v}} / F_{\mathrm{m}}+F_{0} / F_{\mathrm{m}}{ }^{\prime}\right)$. The photochemical quenching (qP) was calculated by using the Kooten and Snel equation (Kooten and Snel 1990).

The average chlorophyll-specific optical absorption cross section $a^{*}$ (normalized to chlorophyll $a$ content, $\mathrm{m}^{2} \mathrm{mg} \mathrm{chl}^{-1}$ ) of the cells was determined according to Falkowski and Raven (1997).

\section{Oxygen evolution measurements}

Oxygen evolution measurements were carried out in triplicate on 2-mL culture samples (chlorophyll content $5 \mathrm{mg} \mathrm{L}^{-1}$ ), using a Liquid-Phase Oxygen Electrode Chamber (Hansatech, DW3) thermostated at $28{ }^{\circ} \mathrm{C}$ and equipped with an oxygen control electrode unit (Hansatech, Oxy-lab). Light was supplied via a red LED light source (Hansatech LH36/2R) at a wavelength of $637 \mathrm{~nm}$ providing a $600-\mu \mathrm{mol}$ photons $\mathrm{m}^{-2} \mathrm{~s}^{-1} \mathrm{PFD}$. The $\mathrm{O}_{2}$ concentration dissolved in the sample was continuously monitored at an acquisition rate of 0.2 reading $\mathrm{s}^{-1}$. Dark respiration rates were measured after the photosynthesis rates had been measured.

Preparation of predator

Poterioochromonas sp. strain ISE1 (CCALA1090; Supplementary Material Fig. S1) was from the Culture Collection of Autotrophic Organisms (CCALA). It was isolated from the central deionized water-producing plant of the Institute of Ecosystem Study (Florence, Italy) and grown in MWC medium (Guillard and Lorenzen 1972) .

\section{Grazing experiments}

Cultures of Synechocystis were grown in $800 \mathrm{~mL}$ PBR and exposed to a PFD of $150 \mu \mathrm{mol} \mathrm{m} \mathrm{m}^{-2} \mathrm{~s}^{-1}$ and maintained at a constant temperature of $28{ }^{\circ} \mathrm{C}$. Cultures were bubbled with air and subjected to a light-dark cycle $(\mathrm{L}=10 \mathrm{~h}, \mathrm{D}=14 \mathrm{~h})$. To assess the effect of $\mathrm{pH}$ on grazing capacity by Poterioochromonas sp., cultures of Synechocystis were contaminated with $1 \%$ of Poterioochromonas cells and exposed to different $\mathrm{pH}$ conditions. 


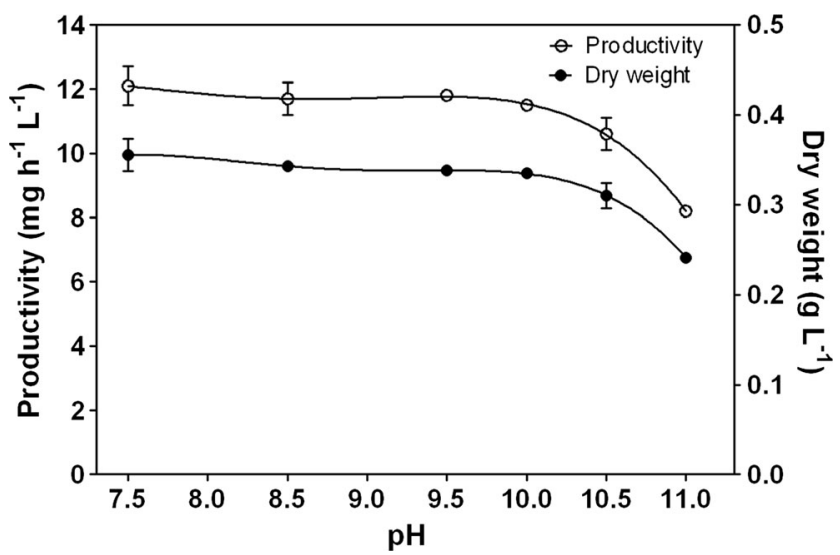

Fig. 1 Changes in productivity and dry weight as a function of $\mathrm{pH}$. Data are the average of at least three measurements; error bars represent the standard deviation

\section{Light microscopy}

Cell suspensions mounted on microscope slides and covered were examined in bright field using a Nikon Eclipse E600. Microscopic fields were photographed using a Nikon digital Sight DS-UV1 digital camera. Digital slide photographs had brightness and contrast optimized to enhance regions of interest. Cell count was carried out using a Bürker-Türk counting chamber.

\section{Results}

\section{Growth characterization of the culture}

The relationship between $\mathrm{pH}$ and productivity is shown in Fig. 1. Synechocystis cultures grown at $\mathrm{pH} 7.5$ showed an optimal productivity. Between $\mathrm{pH} 7.5$ and 10, the reduction of productivity was scarce $(5 \%)$, while a further increase of the $\mathrm{pH}$ to 11.0 caused a drop of productivity of more $30 \%$. Being the dilution rate constant at $0.036 \mathrm{~h}^{-1}$, during the entire duration of the experiments, the reduction in productivity was the result of a corresponding reduction in the dry weight (Fig. 1).
Growth yield $Y_{\mathrm{kJ}}$ (the amount of dry biomass synthesized per kJ of light energy absorbed) reached a maximum value of $5.49 \pm 0.27 \mathrm{mg} \mathrm{kJ}^{-1}$ at $\mathrm{pH} 7.5$ and decreased at increasing $\mathrm{pH}$ (Table 1). As for the reduction in productivity, the drop between $\mathrm{pH} 10$ and 11 was much more apparent. Multiplying the $Y_{\mathrm{kJ}}$ values by the heat of combustion of the biomass, calculated at each $\mathrm{pH}$, it was possible to estimate the PAR-based light conversion efficiency (LCE) for each culture condition (Table 1). LCE ranged between $12.5 \%(\mathrm{pH} 7.5)$ and $8.9 \%(\mathrm{pH} \mathrm{11.0)}$, and the most significant drop was found moving from $\mathrm{pH} 10(11.8 \%)$ to $\mathrm{pH} 11$ (8.9\%) (Table 1).

The actual biomass yield on light energy $(Y)$, that is, the ability of photosynthetic microorganisms to utilize the light energy supplied for biomass formation, decreased as $\mathrm{pH}$ increased in the culture, and it ranged from $1.20 \mathrm{~g}$ biomass mol photons ${ }^{-1}$ at the optimal $\mathrm{pH}$ to $0.89 \mathrm{~g} \mathrm{~mol} \mathrm{photons}^{-1}$ at the highest $\mathrm{pH}$ tested (Table 1).

\section{Fluorescence and photosynthetic parameters}

The maximum quantum yield, calculated by the $F_{\mathrm{v}} / F_{\mathrm{m}}$ ratio, did not change much at the various $\mathrm{pH}$ values and was 0.48 , indicating that Synechocystis' PSII photochemistry was unaffected in the range of $\mathrm{pH}$ 7.5-11.0. NPQ values of chlorophyll fluorescence were found to be very low, and qP was consistently at relatively high values between 0.85 and 0.90 in the range of $\mathrm{pH} 7.5-10.5$, which indicates that most of the absorbed energy was used for photochemistry (Table 2). A NPQ increase and a $\mathrm{qP}$ decrease appears at $\mathrm{pH} 11$. The effective photochemical quantum yield of PSII $\left(\Delta F / F_{\mathrm{m}}{ }^{\prime}\right)$ remained stable at the range of $0.40-0.42$ in all $\mathrm{pH}$ conditions except at $\mathrm{pH} 11.0$ where it decreased by $11 \%(\Delta F /$ $F_{\mathrm{m}}{ }^{\prime}=0.37$ ) (Table 2).

Chlorophyll fluorescence induction kinetics (OJIP) were measured in every experiment. The transients followed the typical polyphasic OJIP rise (Fig. 2). At $\mathrm{pH}$ values from 7.5 to 10.0 , all OJIP parameters remained stable at physiological values. At $\mathrm{pH}$ above $10, M_{0}$ and $V_{\mathrm{J}}$ values increased, indicating a higher rate of closure of the reaction centers and an increment in the net rate of $Q_{\mathrm{A}}$ reduction.
Table 1 Biomass dry weight, productivity, growth yield, actual biomass yield on light energy, and light conversion efficiency (LCE) of Synechocystis grown at different $\mathrm{pH}$ values. Values are mean \pm standard deviations

\begin{tabular}{llllll}
\hline $\mathrm{pH}$ & $\begin{array}{l}\text { Dry weight } \\
\left(\mathrm{mg} \mathrm{L}^{-1}\right)\end{array}$ & $\begin{array}{l}\text { Productivity } \\
\left(\mathrm{mg} \mathrm{L}^{-1} \mathrm{~h}^{-1}\right)\end{array}$ & $Y_{\mathrm{kJ}}\left(\mathrm{mg} \mathrm{kJ}^{-1}\right)$ & $Y\left(\mathrm{~g} \mathrm{~mol} \mathrm{photons}^{-1}\right)$ & LCE (\%) \\
\hline 7.5 & $355 \pm 18$ & $12.1 \pm 0.6$ & $5.49 \pm 0.27$ & $1.20 \pm 0.06$ & $12.5 \pm 0.6$ \\
8.5 & $343 \pm 4$ & $11.7 \pm 0.5$ & $5.31 \pm 0.05$ & $1.16 \pm 0.01$ & $11.9 \pm 0.1$ \\
9.5 & $338 \pm 3$ & $11.8 \pm 0.1$ & $5.24 \pm 0.05$ & $1.15 \pm 0.01$ & $11.9 \pm 0.6$ \\
10.0 & $335 \pm 4$ & $11.5 \pm 0.1$ & $5.20 \pm 0.05$ & $1.14 \pm 0.01$ & $11.8 \pm 0.1$ \\
10.5 & $310 \pm 14$ & $10.6 \pm 0.5$ & $4.88 \pm 0.22$ & $1.07 \pm 0.05$ & $10.7 \pm 0.4$ \\
11.0 & $241 \pm 2$ & $8.2 \pm 0.1$ & $3.94 \pm 0.03$ & $0.89 \pm 0.01$ & $8.9 \pm 0.2$ \\
\hline
\end{tabular}


Table 2 The effective photochemical quantum yield of PSII $\left(\Delta F / F_{\mathrm{m}}{ }^{\prime}\right)$, non-photochemical quenching (NPQ), photochemical quenching coefficient (qP), chlorophyll optical-absorption cross section $\left(a^{*}\right), \mathrm{O}_{2}$ evolution, and respiration rates of Synechocystis cultured at different $\mathrm{pH}$ conditions. Values are mean \pm standard deviations calculated over the steady state for each $\mathrm{pH}$ condition

\begin{tabular}{lllllll}
\hline $\mathrm{pH}$ & $\Delta F / F_{\mathrm{m}}{ }^{\prime}$ & $\mathrm{NPQ}$ & $\mathrm{qP}$ & $a^{*}\left(\mathrm{~cm}^{2} \mathrm{mg} \mathrm{chl}{ }^{-1}\right)$ & $\begin{array}{l}\text { Net } \mathrm{O}_{2} \text { evolution } \\
\left(\mu \mathrm{mol} \mathrm{mg} \mathrm{chl} \mathrm{h}^{-1}\right)\end{array}$ & $\begin{array}{l}\text { Respiration } \\
\left(\mu \mathrm{mol} \mathrm{mg} \mathrm{chl}^{-1} \mathrm{~h}^{-1}\right)\end{array}$ \\
\hline 7.5 & $0.412 \pm 0.007$ & $0.011 \pm 0.005$ & $0.843 \pm 0.004$ & $105 \pm 1$ & $346 \pm 33$ & $22 \pm 3$ \\
8.5 & $0.400 \pm 0.007$ & $0.066 \pm 0.024$ & $0.843 \pm 0.001$ & $110 \pm 1$ & $353 \pm 1$ & $19 \pm 2$ \\
9.5 & $0.400 \pm 0.001$ & $0.054 \pm 0.006$ & $0.857 \pm 0.010$ & $109 \pm 4$ & $320 \pm 4$ & $22 \pm 3$ \\
10.0 & $0.414 \pm 0.007$ & $0.075 \pm 0.007$ & $0.848 \pm 0.008$ & $109 \pm 1$ & $338 \pm 7$ & $24 \pm 1$ \\
10.5 & $0.416 \pm 0.002$ & $0.042 \pm 0.006$ & $0.879 \pm 0.001$ & $112 \pm 7$ & $304 \pm 11$ & $23 \pm 1$ \\
11.0 & $0.370 \pm 0.001$ & $0.129 \pm 0.023$ & $0.818 \pm 0.009$ & $114 \pm 3$ & $398 \pm 21$ & $35 \pm 1$ \\
\hline
\end{tabular}

The values of $\Psi_{0}$ and $\Phi_{\mathrm{E} 0}$ scarcely changed within $\mathrm{pH}=10$, while they decreased by 25 and $35 \%$ at $\mathrm{pH}=11$ respectively, evidencing a reduction in PSII's efficiency (Supplementary Material Table S1).

Synechocystis cells grown at $\mathrm{pH}$ above 10 showed an increased optical chlorophyll cross section of about $10 \%$ compared to cells grown at $\mathrm{pH} 7.5$ (Table 2). Photosynthetic activity measured as oxygen evolution under saturating red light remained stable between $\mathrm{pH} 7.5$ and 10.5 with a mean value of $335 \mu \mathrm{mol} \mathrm{O} \mathrm{mg} \mathrm{chl}^{-1} \mathrm{~h}^{-1}$, while a sharp increase (by $20 \%$ ) was observed at $\mathrm{pH} 11$ (398 $\mu \mathrm{mol} \mathrm{O} \mathrm{O}_{2} \mathrm{chl}^{-1} \mathrm{~h}^{-1}$ ). A similar behavior was observed for dark respiration (oxygen uptake) which scarcely varied between $\mathrm{pH} 7.5$ and 10.5 and increased remarkably at $\mathrm{pH} 11$.

\section{Biochemical biomass characterization}

Elemental composition (\% DW) of dry biomass of Synechocystis, sampled at the steady state of each experiment, is reported in Supplementary Material Table S2. Carbon, nitrogen, and hydrogen contents decreased by approximately

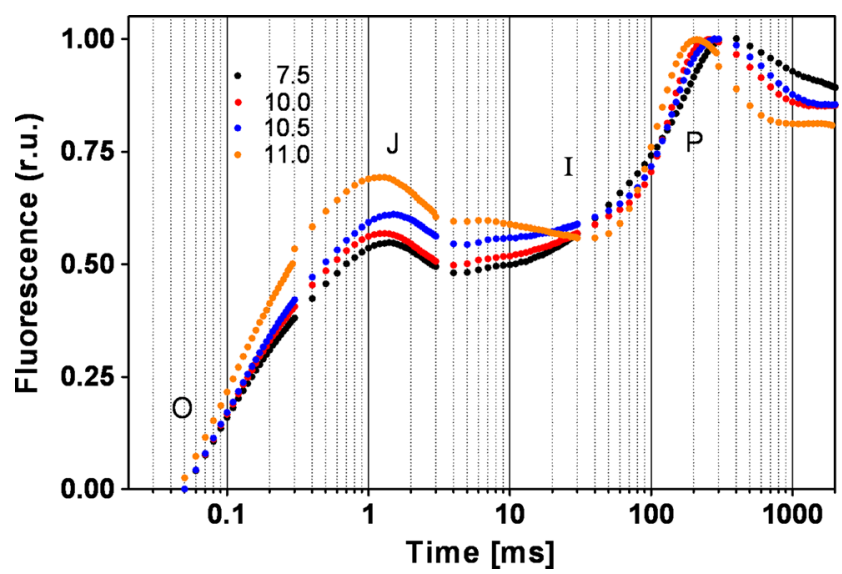

Fig. 2 Effect of the pH on chlorophyll a fluorescence transients of the cells. Transients were normalized in both maximum and initial fluorescence values
$9 \%$ between the lowest and the highest $\mathrm{pH}$. Sulfur content remained stable, except in the culture grown at $\mathrm{pH} 11$ in which it was found to be $14 \%$ lower compared to that at $\mathrm{pH}$ 7.5. Oxygen remained substantially stable around a value of $22 \%$ of the DW. According to the elemental composition of Synechocystis biomass, the molecular mass of a C-mol was $21.83 \mathrm{~g} \mathrm{~mol}^{-1}$ at $\mathrm{pH} 7.5$ and $22.51 \mathrm{~g} \mathrm{~mol}^{-1}$ at $\mathrm{pH}$ 11. Calcium and magnesium contents were stable at $\mathrm{pH} 7.5$ and 10.0 while sodium increased by $32 \%$. At pH 11, sodium, calcium, and magnesium contents increased by $6.7 \times, 6.0 \times$, and $2.8 \times$ times respectively (Supplementary Material Table S2).

Lipid content was stable at $12 \%$ of DW at $\mathrm{pH}$ values between 7.5 and 10.0; at $\mathrm{pH}$ greater than 10.0, it decreased to $9.0 \%$ (Table 3 ). Total protein content remained fairly constant with an average of $65.8 \pm 0.5 \%$ of DW. The amino acid profile of cells grown at three $\mathrm{pH}$ values $(7.5,10.0$, and 11.0) did not show relevant changes (Supplementary Material Table S3). The most abundant amino acids were asparagine (mean 12.25\%) and glutamine (mean $12.94 \%$ ). Carbohydrate content increased as the alkalinity of the medium increased (Table 3). The average ash content of the biomass, at $\mathrm{pH}$ values between 7.5 and 10.5 , was $7.0 \pm 0.1 \%$, while at $\mathrm{pH} 11$, it increased to $11.0 \pm 0.3 \%$. DNA content increased by $14 \%$ between $\mathrm{pH} 7.5$ and 10, while a sharp increase (by $73 \%$ ) was observed at $\mathrm{pH} 11$ (Table 3 ).

$\mathrm{Pc}$ and Apc contents decreased as $\mathrm{pH}$ increased (Table 3). The main carotenoids found in Synechocystis cultures were $\beta$ carotene ( $\beta$-Car), myxoxanthophyll (Myx), zeaxanthin (Zea), and echinenone (Ech). At pH 11, increased Ech and $\beta$-Car contents were observed (Fig. 3). Chlorophyll $\alpha$ content remained at 2.0 to $2.5 \%$ of DW.

Effect of high $\mathrm{pH}$ on contamination level by Poterioochromonas sp.

Two kinetics of $\mathrm{pH}$ rise were compared. For this purpose, two Synechocystis cultures $\left(7.5-8.1 \times 10^{6}\right.$ cells $\left.\mathrm{mL}^{-1}\right)$ were contaminated with Poterioochromonas (initial cell concentration $6.5-7.5 \times 10^{3}$ cells $\mathrm{mL}^{-1}$ ). In one culture, the $\mathrm{pH}$ was rapidly brought to 11 by adding $\mathrm{NaOH}$, while in the other, 
Table 3 Lipid, carbohydrate, protein, DNA, phycocyanin (Pc), allophycocyanin (Apc), and chlorophyll contents of Synechocystis cells cultured at different $\mathrm{pH}$ values. Values are mean \pm standard deviations calculated during the steady state at each $\mathrm{pH}$ condition. (-) not determined

\begin{tabular}{llllllll}
\hline $\mathrm{pH}$ & Lipid (\%) & Carbohydrate (\%) & Protein (\%) & DNA (\%) & Pc (\%) & Apc (\%) & Chlorophyll (\%) \\
\hline 7.5 & $12.1 \pm 1.0$ & $13.5 \pm 0.4$ & $66.0 \pm 2.5$ & $0.227 \pm 0.036$ & $18.6 \pm 0.6$ & $3.76 \pm 0.04$ & $2.57 \pm 0.01$ \\
8.5 & $11.8 \pm 0.3$ & $12.1 \pm 0.2$ & $65.4 \pm 1.3$ & - & $18.2 \pm 0.3$ & $3.98 \pm 0.01$ & $2.12 \pm 0.02$ \\
9.5 & $11.7 \pm 1.4$ & $12.7 \pm 0.5$ & $66.3 \pm 3.5$ & - & $19.5 \pm 0.4$ & $3.23 \pm 0.20$ & $2.54 \pm 0.01$ \\
10.0 & $12.5 \pm 0.1$ & $13.6 \pm 0.1$ & $65.1 \pm 0.4$ & $0.259 \pm 0.046$ & $19.7 \pm 0.3$ & $2.07 \pm 0.34$ & $2.24 \pm 0.01$ \\
10.5 & $9.7 \pm 1.3$ & $14.0 \pm 0.6$ & $66.4 \pm 0.7$ & - & $18.7 \pm 0.5$ & $1.69 \pm 0.22$ & $2.20 \pm 0.07$ \\
11.0 & $9.0 \pm 0.1$ & $18.8 \pm 0.4$ & $65.5 \pm 1.1$ & $0.393 \pm 0.073$ & $13.3 \pm 0.1$ & $2.71 \pm 0.14$ & $2.00 \pm 0.01$ \\
\hline
\end{tabular}

the $\mathrm{pH}$ was left to increase as a result of the photosynthetic growth. In both cultures, $\mathrm{pH}$ was not allowed to exceed 11, by automatically adding $\mathrm{CO}_{2}$. Microscopic analysis of the culture where $\mathrm{pH}$ was rapidly taken to 11 revealed that after $2 \mathrm{~h}$ of exposure, Poterioochromonas cells had completely lost their motility or were spinning on themselves, and at the end of the first light period, no Poterioochromonas cells were detected, while Synechocystis' cell number increased at a rate of $0.0145 \mathrm{~h}^{-1}$ (Fig. 4). However, at the end of the first dark period, Synechocystis' cell number returned approximatively to the initial value, due to a remarkably high cell mortality. During the following light period, Synechocystis' cell number increased, reaching more than 12 million $\mathrm{mL}^{-1}$. Poterioochromonas cells were not detected, neither in the light nor in the dark phase (Fig. 4).

A different behavior was observed where the $\mathrm{pH}$ increase to 11 was achieved physiologically, that is, along with the photosynthetic growth $\left(\mathrm{CO}_{2}\right.$ consumption) (Fig. 5). Under such conditions, after 54 h, Synechocystis almost entirely disappeared and the color of the culture turned yellowish, as a result of the predominance of Poterioochromonas cells. The $\mathrm{pH}$ of the culture during the dark period usually dropped below 11, particularly at the end of the second dark period during which the $\mathrm{pH}$ value declined to 8.3. Poterioochromonas benefited of the drop of $\mathrm{pH}$, becoming more motile and actively grazing Synechocystis. Indeed, at the end of the second dark period, their number increased almost sevenfold, outnumbering Synechocystis cells (Fig. 5).

The role played by the $\mathrm{pH}$ during the dark phase of the cycle was studied in more detail with another experiment in which it was constantly maintained close to 11 by automatic control over the entire light-dark cycle. To minimize stress to the cells, at the start of the culture, the $\mathrm{pH}$ was allowed to reach 11 by growth and thereafter controlled by adding either $\mathrm{NaOH}$ (during the dark) or $\mathrm{CO}_{2}$ (during the light) (Fig. 6). Preventing the drop of $\mathrm{pH}$ during the dark resulted very deleterious for the survival of Poterioochromonas cells which, after an initial increase during which the $\mathrm{pH}$ was slowly rising to 11 (first light period), started to decrease in number during both the light and the dark periods (Fig. 6). Synechocystis cell number remained stable at about 12 million $\mathrm{mL}^{-1}$ in the first $48 \mathrm{~h}$ from the start, and increased up to 23 million $\mathrm{mL}^{-1}$ at the end of the experiment $(80 \mathrm{~h})$.

\section{Discussion}

We found that outdoor cultures of Synechocystis, although grown in a closed photobioreactor, were systematically subjected to severe contamination by Poterioochromonas sp. (ca.
Fig. 3 Changes in $\beta$-carotene ( $\beta$-Car), myxoxanthophyll (Myx), zeaxanthin $(Z e a)$, and echinenone $(E c h)$ detected over the various $\mathrm{pH}$ conditions

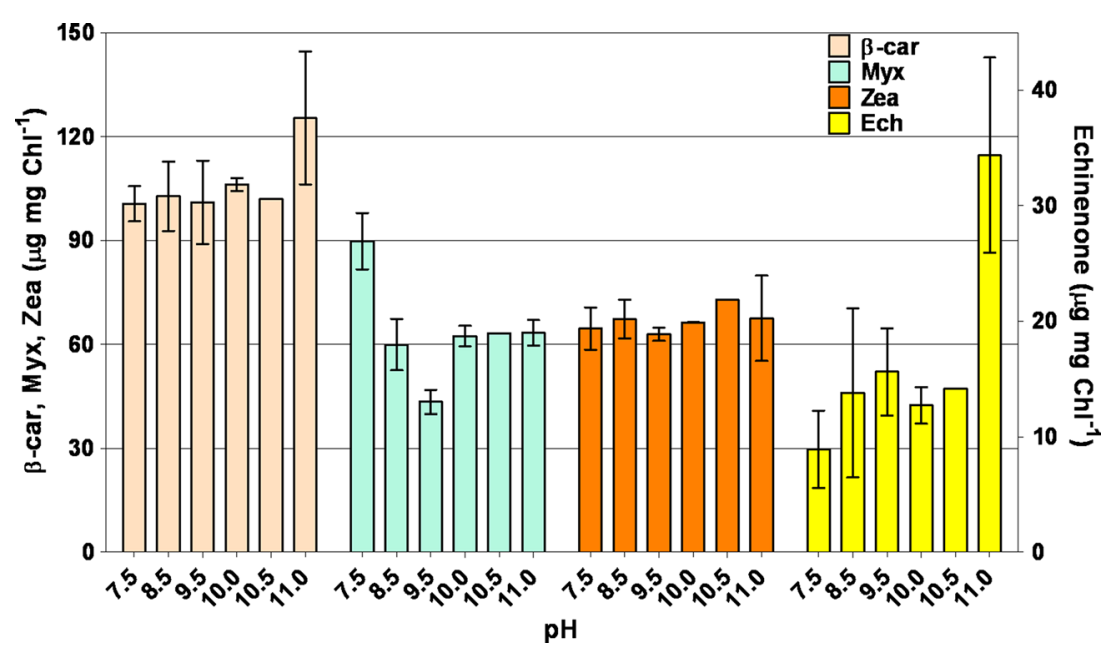




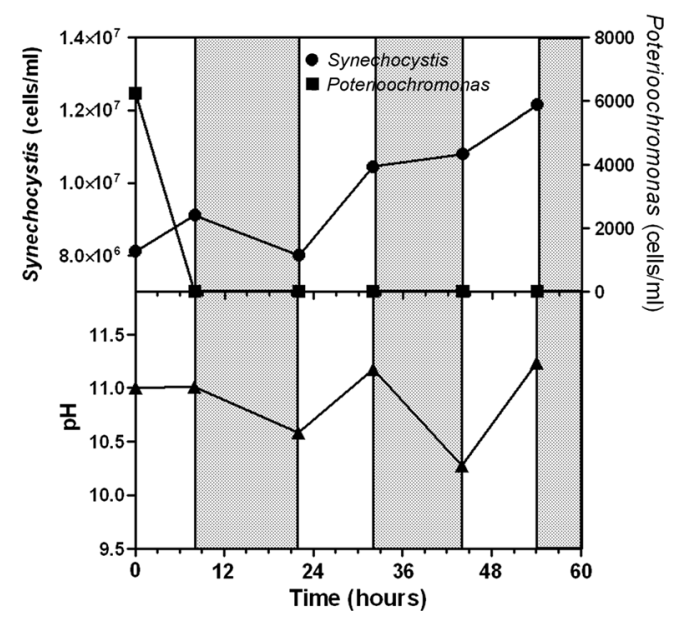

Fig. 4 Effect of $\mathrm{pH}$ on Synechocystis and Poterioochromonas cell number following a sudden rise of the $\mathrm{pH}$ till 11.0 achieved with addition of $\mathrm{NaOH}$ (0.5 M) (light (white bars) and dark (gray bars) phases)

$8 \mu \mathrm{m}$ ) which usually led to their complete loss within 1 week. In fact, as early as 2 days after the inoculation of the PBR outdoors, microscope observation of culture samples revealed the presence of the flagellate microalgae ingesting Synechocystis cells. After 6-7 days, Synechocystis cells had almost entirely disappeared except for sparse cell agglomerates, visible even without the aid of a microscope, while Poterioochromonas cells were blooming; at this stage, the cultures had completely turned to a yellowish color. It was observed that a rise of $\mathrm{pH}$ of the culture close to 11 in the initial stage of the contamination (first 2-3 days from inoculum) resulted in complete disappearance of the flagellate and protozoa within less than $24 \mathrm{~h}$. However, to eradicate Poterioochromonas it was necessary to keep the $\mathrm{pH}$ control active and close to 11 also at night when the $\mathrm{pH}$ usually tends to drop as result of the respiration activity. Therefore, in view

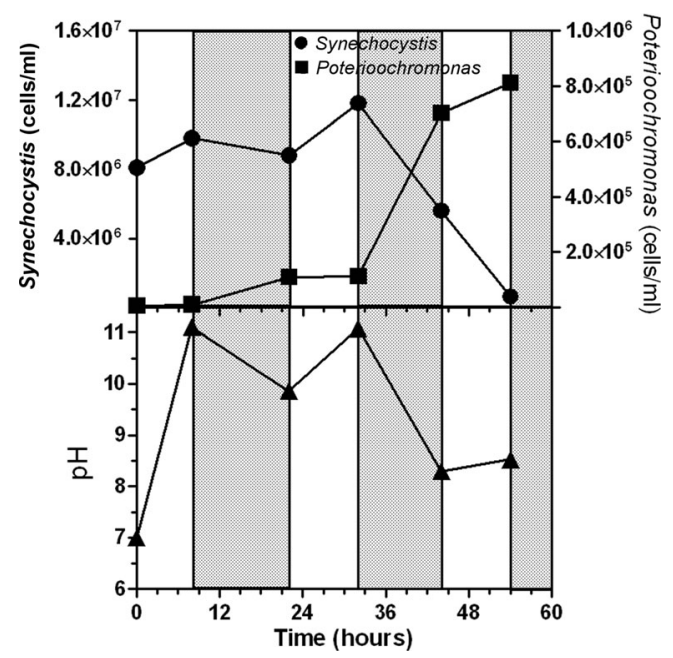

Fig. 5 Effect of pH on Synechocystis and Poterioochromonas cell number when culture $\mathrm{pH}$ was allowed to increase to 11 physiologically by temporarily stopping the $\mathrm{pH}$ control (light (white bars) and dark (gray bars) phases)

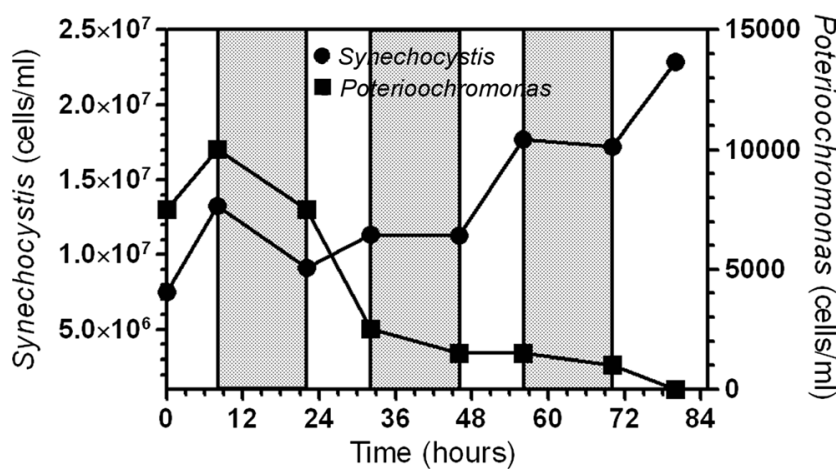

Fig. 6 Effect of $\mathrm{pH}$ on Synechocystis and Poterioochromonas cell number when culture $\mathrm{pH}$ was constantly maintained at 11 by adding either $\mathrm{CO}_{2}$ (light phase (white bars)) or $0.5 \mathrm{M} \mathrm{NaOH}$ (dark phase (gray bars))

of a successful mass cultivation of Synechocystis, we considered of interest to focus on studying the acclimation process of this organism to high alkaline $\mathrm{pH}$ and the effect of such high $\mathrm{pH}$ on a culture's productivity. All the $\mathrm{pH}$ experiments were carried out in a fixed dilution of $0.036 \mathrm{~h}^{-1}$, which in previous experiments proved to be optimal for high light conversion efficiency (Touloupakis et al. 2015). At this dilution rate, the resulting cell concentration of the culture with an optical path of $5 \mathrm{~cm}$ enabled the culture to absorb almost $100 \%$ of the incident light, which is a condition for optimal productivity outdoors.

Synechocystis cultures grown close to neutral $\mathrm{pH}$ showed optimal productivity. Between $\mathrm{pH} 7.5$ and 10, the loss in productivity was negligible (about $8 \%$ ), but increased to $32 \%$ at $\mathrm{pH} 11$. At $\mathrm{pH} 11$, the light conversion efficiency was reduced to $8.9 \%$ and a significant amount of the incident light (about $7 \%$ ) was transmitted by the culture due to the decrease in cell concentration. However, it must be pointed out that since the $\mathrm{pH}$ control of the cultures was achieved by adding $\mathrm{CO}_{2}$, and being it a substrate for photosynthesis, the amount of supplied $\mathrm{CO}_{2}$ directly affected photosynthesis rates and productivity. At $\mathrm{pH} 7$, more $\mathrm{CO}_{2}$ is available for growth. However, there are evidences that when the $\mathrm{pH}$ of the culture is adjusted by adding a buffer, the optimal $\mathrm{pH}$ for growth was higher than 7.5, i.e., close to 10 (Eaton-Rye et al. 2003; Kurian et al. 2006). It has been suggested that at $\mathrm{pH} 10$, an increased coupling of the phycobilisomes to PSII occurs, together with an increased transcript abundance of oxidative stress-responsive genes enhancing resistance of PSII to oxidative stress (Summerfield et al. 2013). Inorganic carbon availability, therefore, is a key factor to consider when setting up a cyanobacterial cultivation. The main forms of dissolved inorganic carbon (DIC) are carbon dioxide, bicarbonate, and carbonate. The equilibrium concentrations between these three species are $\mathrm{pH}$ dependent. At $\mathrm{pH} 10$, the amount of $\mathrm{CO}_{2}$ is zero, while bicarbonate species prevail ( $68 \%$ of total DIC), and the rest is represented by $\mathrm{CO}_{3}{ }^{2-}$ which is not utilizable by the cells. A further increase of $\mathrm{pH}$ to 11 reduces the $\mathrm{HCO}_{3}{ }^{-}$ 
availability to $17.6 \%$. The $\mathrm{pH} 11$ results incompatible for the growth of most of contaminants (ciliates, amoeba, rotifers) and for the survival of Poterioochromonas. At $\mathrm{pH} 11$, Synechocystis cells have still the ability to utilize $\mathrm{HCO}_{3}{ }^{-}$as carbon source, provided the presence of sufficient amount of $\mathrm{Na}^{+}$utilizing the $\mathrm{Na}^{+}$-dependent $\mathrm{HCO}_{3}{ }^{-}$symporter (So et al. 1998; Badger and Price 2003), which may account for the strong accumulation of $\mathrm{Na}$ (6.7-fold) found at $\mathrm{pH} 11$, compared to that at $\mathrm{pH}$ 7.5. Moreover, Synechocystis can rely on a $\mathrm{CO}_{2}$-concentrating mechanism $(\mathrm{CCM})$ which affords intracellular concentrations up to three orders of magnitudes higher than those in the external medium (Kaplan and Reinhold 1999; Giordano et al. 2005). These capabilities allow the organism to cope with harsh environmental conditions without remarkable loss in productivity. On the contrary, Synurophyceae (heterokont) algae, such as Poterioochromonas sp., lack CCMs (Giordano et al. 2005, Ball 2003), and there are evidences that their phagotrophy is light dependent, although only $7 \%$ of their total carbon budget derives from photosynthesis, indicating that there is a necessity for some factor(s) synthesized during autotrophic growth (Caron et al. 1993; Zhang and Watanabe 2001). Moreover, this organism resulted very sensitive to $\mathrm{pH}$ shock, resulting in a rapid loss of its motility followed by cell lysis within a couple of hours when the $\mathrm{pH}$ was suddenly increased to 11 .

The major carotenoids found in Synechocystis cells at the various $\mathrm{pH}$ values were $\beta$-Car, Myx, Zea, and Ech. At $\mathrm{pH} 11$, a higher Ech amount was found. It has been reported that in Synechocystis, Ech can establish a high-affinity bond with the orange carotenoid protein, activating the photoprotection mechanism (Kirilovsky 2007).

Synechocystis' PSII activity, measured as $F_{\mathrm{v}} / F_{\mathrm{m}}$ and oxygen evolution rates, resulted unaffected by high $\mathrm{pH}$ values in the medium. This is in accordance with the study by Summerfield and Sherman where they observed no changes in PSII abundance between neutral and alkaline conditions (Summerfield and Sherman 2008). At pH 11, the rate of photosynthesis was stimulated by about $23 \%$ with respect to $\mathrm{pH} 7.5$, most likely as a result of acclimation of cells to higher light. Indeed, at $\mathrm{pH} 11$, cell concentration (dry weight) decreased, allowing a higher light availability. Moreover, at $\mathrm{pH} 11$, cells need to cope with a higher demand of ATP required by the $\mathrm{HCO}_{3}{ }^{-} / \mathrm{Na}^{+}$symport (Giordano et al. 2005) and by increased maintenance energy (Touloupakis et al. 2015). At very alkaline $\mathrm{pH}$, carbonate mineralization by cyanobacteria is favored, thus forming an external surface layer (S-layer) of cell wall (Kanennaya et al. 2012; Markou and Georgakakis 2011). The increase of sodium, calcium, and magnesium content, at $\mathrm{pH} 11$, supports the increase by $57 \%$ of the ash content.

In conclusion, we report evidence that, in case of contamination by Poterioochromonas sp., an outdoor culture of
Synechocystis is still viable if $\mathrm{pH}$ is maintained above 11 , which allows the complete arrest of such contaminants with an acceptable loss in productivity and no alteration in the biochemical composition of the biomass. This strategy was validated by growing cultures in a large outdoor photobioreactor $(1300 \mathrm{~L})$. Simply switching off the $\mathrm{pH}$ control unit, the culture's $\mathrm{pH}$ naturally rose to values close to 11 during the day, as a result of $\mathrm{CO}_{2}$ uptake during photosynthesis. Night respiration entailed a reduction of $\mathrm{pH}$ to $9.0-9.5$, which must be prevented by keeping $\mathrm{pH}$ at 11 by automatic addition of $\mathrm{NaOH}$ solution.

Acknowledgments We thank Dr. C. Faraloni for her technical assistance with the HPLC analysis, Dr. C. Sili for microscopy photographs and Mr. S. Dodero for his technical assistance with the CHNOS elemental analysis. The research leading to these results has received funding from the European Union Seventh Framework Programme (FP7/2007-2013) under grant agreement number 308518 (CyanoFactory). Amino acid composition analysis was performed by PeptLab (Florence, Italy) (http://www.peptlab.eu/).

\section{Compliance with ethical standards}

Conflict of interest The authors declare that they have no competing interests.

Ethical approval This article does not contain any studies with human participants or animals performed by any of the authors.

Open Access This article is distributed under the terms of the Creative Commons Attribution 4.0 International License (http:// creativecommons.org/licenses/by/4.0/), which permits unrestricted use, distribution, and reproduction in any medium, provided you give appropriate credit to the original author(s) and the source, provide a link to the Creative Commons license, and indicate if changes were made.

\section{References}

Badger MR, Price GD (2003) $\mathrm{CO}_{2}$ concentrating mechanisms in cyanobacteria: molecular components, their diversity and evolution. J Exp Bot 54(383):609-622

Ball LA (2003) Carbon acquisition in the crysophyte algae. $\mathrm{PhD}$ thesis. Univ. Dundee, Dundee

Battchikova N, Vainonen JP, Vorontsova N, Keranen M, Carmel D, Aro EM (2010) Dynamic changes in the proteome of Synechocystis 6803 in response to $\mathrm{CO}_{2}$ limitation revealed by quantitative proteomics. J Proteome Res 9:5896-5912

Bennett A, Bogorad L (1973) Complementary chromatic adaptation in a filamentous blue-green alga. J Cell Biol 58(2):419-435

Blom JF, Pernthaler J (2010) Antibiotic effects of three strains of chrysophytes (Ochromonas, Poterioochromonas) on freshwater bacterial isolates. FEMS Microbiol Ecol 71(2):281-290

Carney LT, Lane TW (2014) Parasites in algae mass culture. Front Microbiol 5:278

Caron DA, Sanders RW, Lim EL, Marrasé C, Amaral LA, Whitner S, Aoki RB, Porter KG (1993) Light-dependent phagotrophy in the freshwater mixotrophic chrysophyte Dinobryon cylinadricum. Microb Ecol 25:93-111 
Chaves JE, Kirst H, Melis A (2015) Isoprene production in Synechocystis under alkaline and saline growth conditions. J Appl Phycol 27: 1089-1097

Dubois M, Gilles KA, Hamilton JK, Rebers PA, Smith F (1956) Colorimetric method for determination of sugars and related substances. Anal Chem 28:350-356

Eaton-Rye JJ, Shand JA, Nicoll WS (2003) pH-dependent photoautotrophic growth of specific photosystem II mutants lacking lumenal extrinsic polypeptides in Synechocystis PCC 6803. FEBS Lett 543(1-3):148-153

Englund E, Pattanaik B, Ubhayasekera SJK, Stensjö K, Bergquist J, Lindberg P (2014) Production of squalene in Synechocystis sp. PCC 6803. PLoS One 9(3):e90270

Falkowsky PG, Raven JA (1997) Aquatic photosynthesis. Blackwell Science, New York

Forehead H, O'Kelly CJ (2013) Small doses, big troubles: modeling growth dynamics of organisms affecting microalgal production cultures in closed photobioreactors. Bioresour Technol 129:329-334

Gao Z, Zhao H, Li Z, Tan X, Lu X (2012) Photosynthetic production of ethanol from carbon dioxide in genetically engineered cyanobacteria. Energy Environ Sci 5:9857-9865

Giannelli L, Scoma A, Torzillo G (2009) Interplay between light intensity, chlorophyll concentration and culture mixing on the hydrogen production in sulfur-deprived Chlamydomonas reinhardtii cultures grown in laboratory photobioreactors. Biotechnol Bioeng 104:76-90

Giordano M, Beardall J, Raven JA (2005) $\mathrm{CO}_{2}$ concentrating mechanisms in algae: mechanisms, environmental modulation, and evolution. Annu Rev Plant Biol 56:99-131

Guillard and Lorenzen (1972) Yellow-green algae with chlorophyllide $c$. J Phycol 8:10-14

Hoffman Y, Aflalo C, Zarka A, Gutman J, James TY, Boussiba S (2008) Isolation and characterization of a novel chytrid species (phylum Blastocladiomycota), parasitic on the green alga Haematococcus. Mycol Res 112:70-81

Holen DA, Boraas ME (1995) Mixotrophy in chrysophytes. In: Sandgren CD, Smol JP, Kristiansen J (eds) Chrysophyte algae: ecology, phylogeny and development. Cambridge University Press, Cambridge, pp. $119-140$

Kaplan A, Reinhold L (1999) $\mathrm{CO}_{2}$ concentrating mechanisms in photosynthetic microorganisms. Annu Rev Plant Physiol Mol Biol 50: 539-570

Kamennaya NA, Ajo-Franklin CM, Northen T, Jansson C (2012) Cyanobacteria as biocatalysts for carbonate mineralization. Minerals 2:338-364

Kirilovsky D (2007) Photoprotection in cynobacteria: the orange carotenoid protein (OCP)-related non-photochemical-quenching mechanism. Photosynth Res 93:7-16

Kooten O, Snel JFH (1990) The use of chlorophyll fluorescence nomenclature in plant stress physiology. Photosynth Res 25(3):147-150

Krause GH, Jahns P (2004) Non-photochemical energy dissipation determined by chlorophyll fluorescence quenching: characterization and function. In: Papageorgiou GC, Govindjee A, (eds). Chlorophyll a fluorescence. Advances in photosynthesis and respiration. Dordrecht, Kluwer Academic Publishers, pp 463-495.

Kurian D, Phadwal K, Mäenpää P (2006) Proteomic characterization of acid stress response in Synechocystis sp. PCC 6803. Proteomics 6(12):3614-3624

Leeper DA, Porter KG (1995) Toxicity of the mixotrophic chrysophyte Poterioochromonas malhamensis to the cladoceran Daphnia ambigua. Arch Hydrobiol 134:207-222
Lopo M, Montagud A, Navarro E, Cunha I, Zille A, de Córdoba PF, Moradas-Ferreira P, Tamagnini P, Urchueguía JF (2012) Experimental and modeling analysis of Synechocystis sp. PCC 6803 growth. J Mol Microbiol Biotechnol 22(2):71-82

Lowry O, Rosebrough N, Farr A, Randall R (1951) Protein measurement with the folin phenol reagent. J Biol Chem 193: 265-275

Maestri O, Joset F (2000) Regulation by external pH and stationary growth phase of the acetolactate synthase from Synechocystis PCC 6803. Mol Microbiol 37:828-838

Markou G, Georgakakis D (2011) Cultivation of filamentous cyanobacteria (blue-green algae) in agro-industrial wastes and wastewaters: a review. Appl Ener 88:3389-4301

McGinn PJ, Dickinson KE, Bhatti S, Frigon JC, Guiot SR, O'Leary SJ (2011) Integration of microalgae cultivation with industrial waste remediation for biofuel and bioenergy production: opportunities and limitations. Photosyn Res 109: 231-247

Potenza M, Sabatino G, Giampi F, Rosi L, Papini AM, Dei L (2013) Analysis of egg-based model wall paintings by use of an innovative combined dot-ELISA and UPLC-based approach. Anal Bioanal Chem 405:691-701

Pikuta EV, Hoover RB (2007) Microbial extremophiles at the limits of life. Crit Rev Microbiol 33(3):183-209

Rego D, Redondo LM, Geraldes V, Costa L, Navalho J, Pereira MT (2015) Control of predators in industrial scale microalgae cultures with pulsed electric fields. Bioelectrochemistry 103:60-64

Sharma NK, Tiwari SP, Tripathi KN, Rai AK (2011) Sustainability and cyanobacteria (blue-green algae): facts and challenges. J Appl Phycol 23:1059-1081

So AKC, Kassan A, Espie GS (1998) $\mathrm{Na}^{+}$-dependent $\mathrm{HCO}_{3}{ }^{-}$transport in the cyanobacterium Synechocystis PCC 6803. Can J Bot 76: 1084-1091

Summerfield TC, Sherman LA (2008) Global transcriptional response of the alkali tolerant cyanobacterium Synechocystis sp. strain PCC 6803 to a pH 10 environment. Appl Environ Microbiol 74: $5276-5284$

Summerfield TC, Crawford TS, Young RD, Chua JP, Macdonald RL, Sherman LA, Eaton-Rye JJ (2013) Environmental pH affects photoautotrophic growth of Synechocystis sp. PCC 6803 strains carrying mutations in the lumenal proteins of PSII. Plant Cell Physiol 54(6):859-874

Touloupakis E, Cicchi B, Torzillo G (2015) Bioenergetic assessment of photosynthetic Synechocystis sp. PCC 6803 growth in continuous cultures. Biotechnol Biofuels 8:133.

Yu Y, You L, Liu D, Hollinshead W, Tang YJ, Zhang F (2013) Development of Synechocystis sp. PCC 6803 as a phototrophic cell factory. Mar Drugs 11(8):2894-2916

Van Heukelem L, Thomas CS (2001) Computer-assisted high performance liquid chromatogaphy method development with applications to the isolation and analysis of phytoplankton pigments. $\mathrm{J}$ Chromatogr A 910:31-49

Zemke PE, Sommerfeld MR, Hu Q (2013) Assessment of key biological and engineering design parameters for production of Chlorella zofingiensis (Chlorophyceae) in outdoor photobioreactors. Appl Microbiol Biotechnol 97(12):5645-5655

Zhang X, Watanabe MM (2001) Grazing and growth of the mixotrophic chrysomonad Poterioochromonas malhamensis (Chrysophyceae) feeding on algae. J Phycol 37:738-743 